\title{
INTERLEUKIN-10 RELEASE RELATED TO CARDIOPULMONARY BYPASS IN INFANTS UNDERGOING CARDIAC OPERATIONS
}

Marie-Christine Seghaye, $\mathrm{MD}^{\mathrm{a}}$

Jean Duchateau, MD ${ }^{\mathrm{c}}$

Jacqueline Bruniaux, MD $^{\mathbf{a}}$

Serge Demontoux, $\mathrm{MD}^{\mathrm{a}}$

Catherine Bosson, $\mathrm{MD}^{\mathrm{a}}$

Alain Serraf, MD $^{\text {b }}$

Gilles Lecronier, $\mathrm{MD}^{\mathrm{a}}$

Emir Mokhfi, MD ${ }^{\mathrm{a}}$

Claude Planché, $\mathrm{MD}^{\mathrm{b}}$
To evaluate cytokine balance related to cardiopulmonary bypass, we prospectively investigated 11 infants undergoing cardiac operations for congenital heart disease. Proinflammatory cytokines (tumor necrosis factor- $\alpha$ and interleukin-8) and the antiinflammatory cytokine interleukin-10 were measured at multiple time points before, during, and after bypass. Tumor necrosis factor- $\alpha$ and interleukin-8 values were within normal range before the operation. These values increased significantly during bypass, reaching their peaks after protamine administration (tumor necrosis factor- $\alpha, 133.6 \pm 124.9 \mathrm{pg} / \mathrm{ml}$; mean \pm standard deviation; $p<0.005$ ) and 2 hours after termination of the procedure (interleukin-8, $92.1 \pm 44.1$ $\mathrm{pg} / \mathrm{ml} ; p<0.01$ ). Tumor necrosis factor- $\alpha$ and interleukin-8 equaled normal prebypass values from the first postoperative day on. Interleukin-10 levels were within normal range before the operation and were already significantly increased 10 minutes after initiation of bypass (interleukin-10, $39.4 \pm 34.3 \mathrm{pg} / \mathrm{ml} ; \boldsymbol{p}<0.05$ ). These levels remained elevated throughout the procedure but returned to normal after protamine administration. A second significant release of interleukin-10 occurred from the early postoperative period on, reaching its peak 24 hours after termination of cardiopulmonary bypass (interleukin-10, 351.6 $\pm 304.0 \mathrm{pg} / \mathrm{ml} ; p<0.01$ ). Interleukin-10 values were normal on the second postoperative day in all patients. Interleukin-10 kinetics showed an inverse pattern compared with tumor necrosis factor- $\alpha$ and interleukin-8. This difference suggests an interplay between proinflammatory and antiinflammatory cytokines released during and after cardiopulmonary bypass. Interleukin-10 levels measured 4 and 24 hours after bypass strongly correlated with the degree of hypothermia during bypass (Spearman's correlation coefficient, $\mathbf{- 0 . 7 7}$ $[p<0.01]$ and $-0.89[p<0.0005]$, respectively); these levels did not correlate with duration of bypass and aortic crossclamping, however. This result suggests that besides immunologically mediated production of interleukin-10, hypothermia itself could modulate interleukin-10 production. In conclusion, this study demonstrates interleukin-10 production, in addition to interleukin-8 and tumor necrosis factor- $\alpha$ synthesis, in response to cardiopulmonary bypass in infants. Interleukin-10 could play a protective role by down-regulating proinflammatory cytokine release during and after cardiopulmonary bypass. (J THORAC CARDIOvASC SURG 1996; 111:545-53)
From the Departments of Pediatric Cardiac Intensive Care ${ }^{\mathbf{a}}$ and

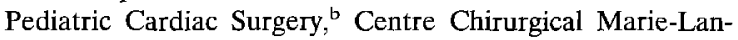
nelongue, Le Plessis-Robinson, France, and the Department of Immunology, ${ }^{\mathrm{c}}$ Hopitaux Universitaires Brugmann et SaintPierre, Brussels, Belgium.

Received for publication Feb. 3, 1995; accepted for publication May 23, 1995.
Address for reprints: Marie-Christine Seghaye, MD, Department of Pediatric Cardiology, RWTH Aachen, Pauwelsstrasse D, 52057 Aachen, Germany.

Copyright (c) 1996 by Mosby-Year Book, Inc.

$0022-5223 / 96 \$ 5.00+0 \quad \mathbf{1 2 / 1 / 6 6 4 5 9}$ 
C ardiopulmonary bypass (CPB) induces complex inflammatory mechanisms, including the synthesis of proinflammatory cytokines such as tumor necrosis factor- $\alpha$ (TNF- $\alpha$ ), interleukin (IL)-1, IL-6, and IL-8, all of which may be related in part to postoperative complications. ${ }^{1-5}$ Several stimuli (including complement anaphylatoxins produced during $\mathrm{CPB}^{6,7}$ ) induce TNF- $\alpha$ synthesis by activated monocytes and macrophages. ${ }^{8}$ TNF- $\alpha$ plays a major role in the pathophysiology of sepsis ${ }^{8}$ and is thought to be implicated in the development of complications after cardiac operations, such as capillary leak syndrome and multisystem organ failure. ${ }^{1,9}$ IL-8 is produced by several circulating and noncirculating cells in response to stimuli, such as IL-1 and TNF$\alpha .{ }^{10} \mathrm{IL}-8$ is a potent polymorphonuclear and T-lymphocyte chemotactic factor that increases endothelial cell-polymorphonuclear leukocyte interactions. ${ }^{11} \mathrm{Be}$ cause of its increased synthesis by monocytes submitted to anoxic preconditioning and oxygen stress, IL-8 may play a role in ischemia-reperfusion injury. ${ }^{12}$

Whether the synthesis of antiinflammatory interleukins ${ }^{13}$ controls the production of proinflammatory cytokines in the setting of $\mathrm{CPB}$ remains unknown. IL-10, a recently characterized natural antiinflammatory interleukin, regulates the function of several cell types. ${ }^{14,15}$ IL-10 suppresses the in vitro production of TNF- $\alpha, \mathrm{IL}-1, \mathrm{IL}-6$, and IL$8,{ }^{16,17}$ as well as its own production. ${ }^{18}$ It also enhances the lipopolysaccharide-induced macrophage production of the IL-1 receptor antagonist. ${ }^{19}$ In a murine model of sepsis, IL-10 reduces lipopolysaccharide-related toxicity ${ }^{20}$ and, in vitro, IL-10 inhibits the induction of monocyte procoagulant activity by bacterial lipopolysaccharides. ${ }^{21}$ IL-10 also blocks up-regulation of pulmonary vascular intracellular adhesion molecule- 1 in an animal model of immune complex-induced lung injury. ${ }^{22} \mathrm{IL}-10$ is produced during sepsis, ${ }^{23,24}$ and the role of TNF- $\alpha$ as a mediator for its synthesis in human endotoxemia has been addressed. ${ }^{25}$ Recently, IL-10 secretion in adult patients undergoing CPB has been observed. $^{26}$

The aim of our study was to analyze cytokine balance related to CPB in infants by measuring the secretion of the antiinflammatory IL-10 in addition to the secretion of the proinflammatory cytokines TNF- $\alpha$ and IL-8.

\section{Patients and methods}

Clinical. Eleven infants aged 2 to 10 months (median 3 months) undergoing $\mathrm{CPB}$ for congenital cardiac defects were prospectively enrolled in this study. Patient data and type of surgical procedure are shown in Table I.

Anesthesia and $C P B$ protocol. Conventional general anesthesia and curarization, achieved with diazepam, fentanyl sulfate, and pancuronium bromide, were used in all patients. Nasotracheal intubation and placement of central venous and peripheral arterial catheters were performed after induction of anesthesia. At the end of the surgical procedure, left atrial and pulmonary arterial catheters were placed if necessary for postoperative care. Antibiotic prophylaxis consisted of cefazolin $(25 \mathrm{mg} / \mathrm{kg})$ at induction of anesthesia and at the end of the surgical procedure. Patients did not receive corticosteroids during the study period.

CPB was conducted according to the previously described technique. ${ }^{27}$ In brief, a roller pump inducing a nonpulsating flow, a hollow fiber membrane oxygenator, and a heat exchanger for cooling and rewarming were used. Priming volume consisted of compatible packed red cells, fresh frozen plasma, and sodium bicarbonate $(8.4 \%)$. CPB was established after aortic and bicaval cannulation with a flow rate of $2.4 \mathrm{~L} / \mathrm{m}^{2}$ per minute, which was maintained throughout the procedure. A left ventricular vent was placed through the right superior pulmonary vein. After aortic crossclamping, cardioplegia was achieved with an intraaortic injection of Bretschneider's solution $(5$ to $10 \mathrm{ml} / \mathrm{kg}$ ) followed 30 minutes later by an injection of a Ringer's lactate potassium solution (15 $\mathrm{ml} / \mathrm{kg}$ ) with oxygenated blood $(5 \mathrm{ml} / \mathrm{kg})$. Heparinization was achieved with heparin sulfate $(3 \mathrm{mg} / \mathrm{kg})$ and its effects were neutralized at the end of the procedure with protamine sulfate, which was titrated according to the measured circulating heparin level.

Postoperative care. Patients were cared for in the pediatric intensive care unit. Continuous monitoring of hemodynamic parameters (heart rate and rhythm and systemic arterial, central venous, pulmonary arterial, and left atrial pressures) and measurement of urine output were continued for as long as necessary, but at least for 24 hours. Inotropic and systemic or pulmonary vasodilator treatment (or both) were adapted to hemodynamic parameters. Routine blood examinations included blood gas analysis, determination of serum electrolyte values, and coagulation tests (thrombin time, partial thromboplastin time, fibrinogen, thrombocyte count). Aspartate aminotransferase was repeatedly measured during the first 3 days after the operation. The ratio of arterial oxygen tension $\left(\mathrm{PaO}_{2}\right)$ to inspired oxygen fraction $\left(\mathrm{Fio}_{2}\right)$ was used as the oxygenation parameter in patients receiving mechanical ventilation.

Cytokine determination. TNF- $\alpha$, IL- 8 , and IL-10 were determined by means of an immunoenzymetric assay from Medgenix, Fleurus, Belgium, according to the manufacturer's recommendations. It is a solid-phase enzymeamplified sensitivity immunoassay performed on microtiter plates, based on the oligoclonal system, in which several monoclonal antibodies directed against distinct epitopes of the cytokines are used, allowing high sensitivity. Specificity of the assays has been controlled by the manufacturer by excluding cross reactivity toward 25 cytokines or growth factors. Accuracy of the determinations was also controlled by demonstrating greater than 
Table I. Patient data

\begin{tabular}{cclll}
\hline Patient No. & Age $(\mathrm{mo})$ & \multicolumn{1}{c}{ Diagnosis } & \multicolumn{1}{c}{ Surgical procedure } & Postop. complications \\
\hline 1 & 3.5 & DORV, large VSD, PAB & VSD closure, debanding & Heart failure \\
2 & 2.5 & VSD, PHT & VSD closure & None \\
3 & 4.5 & VSD, PHT & VSD closure & None \\
4 & 8.5 & Down, AVSD, PHT & AVSD repair & None \\
5 & 10 & Tetralogy of Fallot & Repair & None \\
6 & 3 & Down, AVSD, PHT & AVSD repair & PHT \\
7 & 2.5 & Down, AVSD, PHT & AVSD repair & Heart failure, PHT \\
8 & 2.5 & Down, AVSD, PHT & AVSD repair & Heart failure, PHT, CLS, DIC \\
9 & 4 & VSD, PHT & VSD closure & None \\
10 & 2 & VSD, PHT & VSD closure & None \\
11 & 8 & Tetralogy of Fallot & Repair & None \\
\hline
\end{tabular}

DORV, Double-outlet right ventricle; $V S D$, ventricular septal defect; $P A B$, pulmonary arterial banding; $P H T$, pulmonary hypertension; Down, Down syndrome; $A V S D$, atrioventricular septal defect; $C L S$, capillary leak syndrome; $D I C$, disseminated intravascular coagulation.

95\% recovery when purified cytokine was purposely added in samples of plasma, serum, or cell culture medium in concentration ranges covering the entire spectrum of the standard curve (up to $1500 \mathrm{pg} / \mathrm{ml}$ for TNF- $\alpha$, up to 750 $\mathrm{pg} / \mathrm{ml}$ for IL-8, and up to $1335 \mathrm{pg} / \mathrm{ml}$ for IL-10). In each test run, control samples with known concentrations were assessed in the low- and high-range levels of the assay. The minimum detectable concentrations are $3 \mathrm{pg} / \mathrm{ml}$ for TNF- $\alpha, 0.7 \mathrm{pg} / \mathrm{ml}$ for IL-8, and $1 \mathrm{pg} / \mathrm{ml}$ for IL-10. In plasma of normal adults, expected TNF- $\alpha$ values are less than $20 \mathrm{pg} / \mathrm{ml}$, IL-8 values range between 0 and $47 \mathrm{pg} / \mathrm{ml}$, and IL-10 values average $2.45 \pm 3.2 \mathrm{pg} / \mathrm{ml}$ (mean \pm standard deviation).

Blood samples were collected after induction of anesthesia, 10 minutes after the onset of CPB, 5 minutes after removal of the aortic crossclamp, at the end of CPB before protamine administration, 10 minutes after protamine administration, and $2,4,12,24$, and 48 hours after termination of CPB. Blood was withdrawn from a peripheral arterial catheter before and after CPB and simultaneously from the arterial line and the left vent during CPB. For each sample, $1 \mathrm{ml}$ of blood was taken in plastic tubes containing ethylenediaminetetraacetic acid. Blood was immediately centrifuged (3000 rpm for 10 minutes) and separated plasma was frozen at $-70^{\circ} \mathrm{C}$ until assay.

Statistical analysis. Results are expressed in the text and in Table II as the mean value \pm 1 standard deviation and in the figures as the mean value \pm standard error of the mean. Data were analyzed with SYSTAT software (The System for Statistics, SYSTAT, Inc., 1990, Evanston, IIl.). For statistical analysis of cytokine variation in comparison with prebypass values, the nonparametric Wilcoxon test was used. Spearman's rank correlation coefficient was assessed for correlation of independent parameters, and $p$ values less than 0.05 were considered significant.

\section{Results}

Clinical. Durations of CPB and aortic crossclamping were $96.8 \pm 40.5$ minutes (mean \pm standard deviation) and $53.7 \pm 24.1$ minutes, respectively. Minimal rectal temperature averaged $27.6 \pm$
Table II. Clinical data

$\begin{array}{lc}\mathrm{CPB}(\mathrm{min}) & 96.8 \pm 40.5 \\ \mathrm{AXT}(\mathrm{min}) & 53.7 \pm 24.1 \\ \text { Temperature }\left({ }^{\circ} \mathrm{C}\right) & 27.6 \pm 2.3 \\ \text { Inotropic support }(n) & 3 \\ \text { Pulmonary vasodilator }(n) & 3 \\ \mathrm{PaO}_{2} / \mathrm{FiO}_{2}(\mathrm{H} 2) & 25.7 \pm 14.3 \\ \mathrm{PaO}_{2} / \mathrm{FiO}_{2}(\mathrm{H} 4) & 26.7 \pm 11.3 \\ \mathrm{PaO}_{2} / \mathrm{FiO}_{2} \text { (H12) } & 27.7 \pm 18.1 \\ \mathrm{Mechanical} \mathrm{ventilation}(\mathrm{hr}) & 222 \pm 308\end{array}$

$C P B$, Duration of cardiopulmonary bypass; $A X T$, duration of aortic crossclamping; temperature, minimal rectal temperature; $\mathrm{PaO}_{2} / \mathrm{FiO}_{2}(\mathrm{H} 2)$, (H4), (H12), $\mathrm{PaO}_{2} / \mathrm{FiO}_{2} 2,4$, and 12 hours after termination of CPB. Results are expressed by the mean value \pm standard deviation.

$2.3^{\circ} \mathrm{C}$. No correlation was observed between duration of CPB, duration of aortic crossclamping, and minimal rectal temperature during CPB. Three patients with postoperative heart failure (patients 1,7 , and 8) received inotropic support, and three patients with pulmonary hypertension (patients 6,7 , and 8) received pulmonary vasodilator treatment. The ratio $\mathrm{PaO}_{2} / \mathrm{FiO}_{2}$ calculated at several time points during the first postoperative day is shown in Table II. Lungs of the patients were mechanically ventilated for $222 \pm 308$ hours (median 84 hours). Maximal aspartate aminotransferase values measured within the first 12 hours after the operation averaged $188 \pm 74 \mathrm{IU} / \mathrm{L}$. Important capillary leak syndrome developed in patient 9 , with laboratory evidence of disseminated intravascular coagulation. All infants were discharged home. Table II summarizes clinical data of our patients.

Circulating cytokines. The perioperative cytokine values were obtained from blood samples obtained from peripheral arterial and oxygenator arterial lines. 


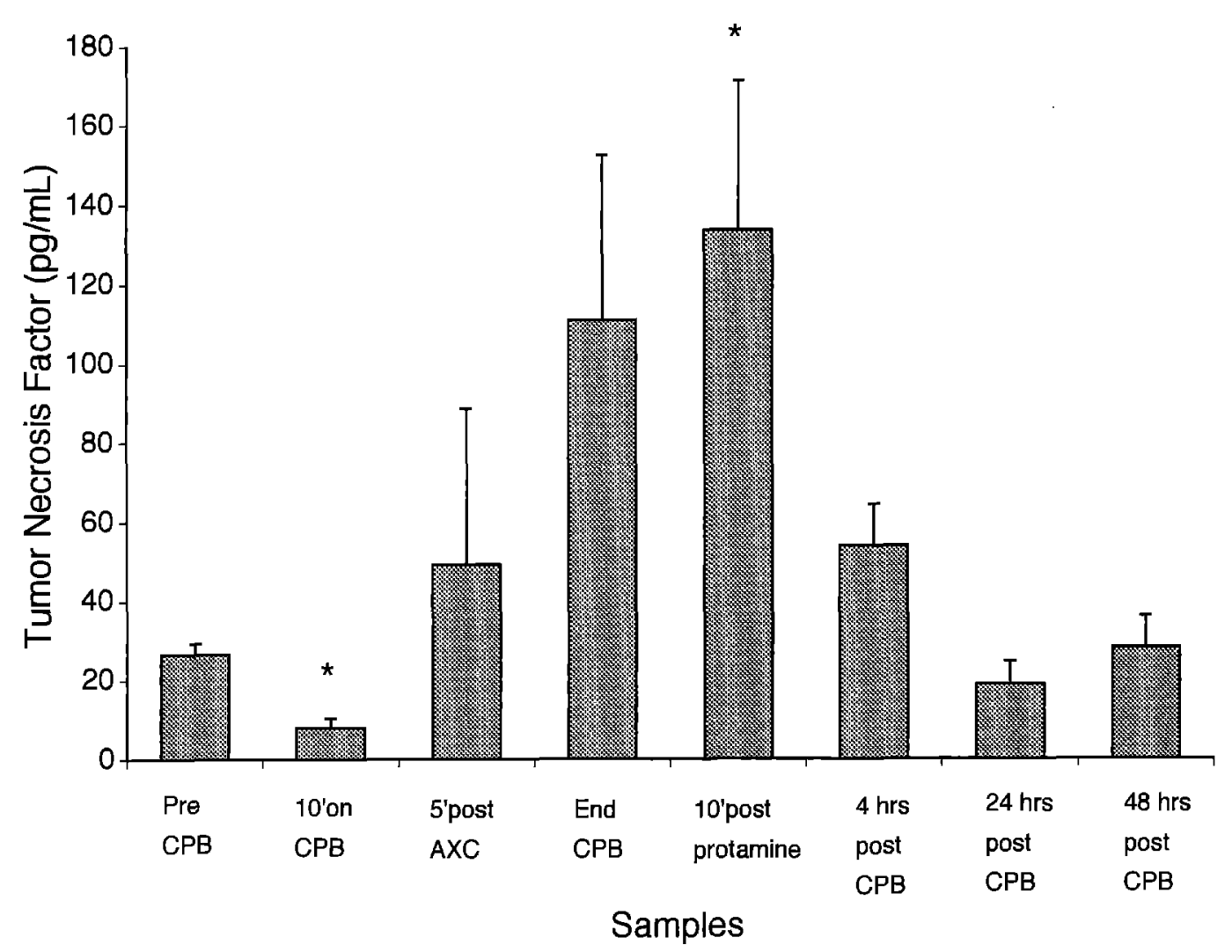

Fig. 1. Course of TNF- $\alpha$ before, during, and after CPB in 11 infants. Values are expressed by mean \pm standard error of the mean. *Significant differences in TNF- $\alpha$ levels versus prebypass values $(p<0.05)$. $C P B$, Cardiopulmonary bypass; $A X C$, aortic crossclamp time. For specification of sample times, see text.

The transpulmonary cytokine gradient during CPB is specified.

$T N F-\alpha$. TNF- $\alpha$ concentrations rose significantly during CPB (prebypass values $26.5 \pm 9.7 \mathrm{pg} / \mathrm{ml}$, mean \pm standard deviation) to peak values 10 minutes after administration of protamine $(136.6 \pm$ $124.9 \mathrm{pg} / \mathrm{ml} ; p<0.005)$. TNF- $\alpha$ concentrations decreased from the immediate postoperative period on and reached prebypass values on the first postoperative day. During CPB, no transpulmonary TNF- $\alpha$ gradient was present. There was no correlation between TNF- $\alpha$ values and minimal temperature, duration of CPB, and duration of aortic crossclamping. TNF- $\alpha$ levels measured 4 and 24 hours after CPB correlated with maximal concentrations of aspartate aminotransferase (Spearman's correlation coefficient, 0.69 and 0.86 , respectively; $p<$ 0.05 ). Fig. 1 shows the course of TNF- $\alpha$ before, during, and after CPB.

IL-8. IL-8 concentrations rose significantly during CPB from prebypass values $(9.0 \pm 5.7 \mathrm{pg} / \mathrm{ml}$, mean \pm stamdard deviation) to peak values 2 hours after termination of CPB $(92.1 \pm 44.1 \mathrm{pg} / \mathrm{ml} ; p<$ 0.01 ). IL-8 concentration decreased slowly on the day of operation and reached pre-CPB values from the first postoperative day on. During $\mathrm{CPB}$, no transpulmonary IL-8 gradient was present. No correlation existed between IL-8 levels and minimal temperature or duration of CPB and aortic crossclamping. IL-8 levels did not correlate with the $\mathrm{PaO}_{2} / \mathrm{Fio}_{2}$ ratio calculated during the study period or with the duration of mechanical ventilation. IL-8 measured 12 and 24 hours after CPB correlated with maximal aspartate aminotransferase (Spearman's correlation coefficient, $0.62 ; p<0.05$ ). Fig. 2 depicts the course of IL- 8 before, during, and after CPB.

IL-10. IL-10 increased significantly from prebypass values to values 10 minutes after the start of CPB $(8.4 \pm 4.9 \mathrm{pg} / \mathrm{ml}$ [mean \pm standard deviation] vs $39.4 \pm 34.3 \mathrm{pg} / \mathrm{ml} ; p<0.02$ ), remaining elevated after removal of the aortic crossclamp and at the end of CPB. IL-10 values after protamine administration tended to return to normal. In comparison with prebypass values, IL-10 levels were significantly 


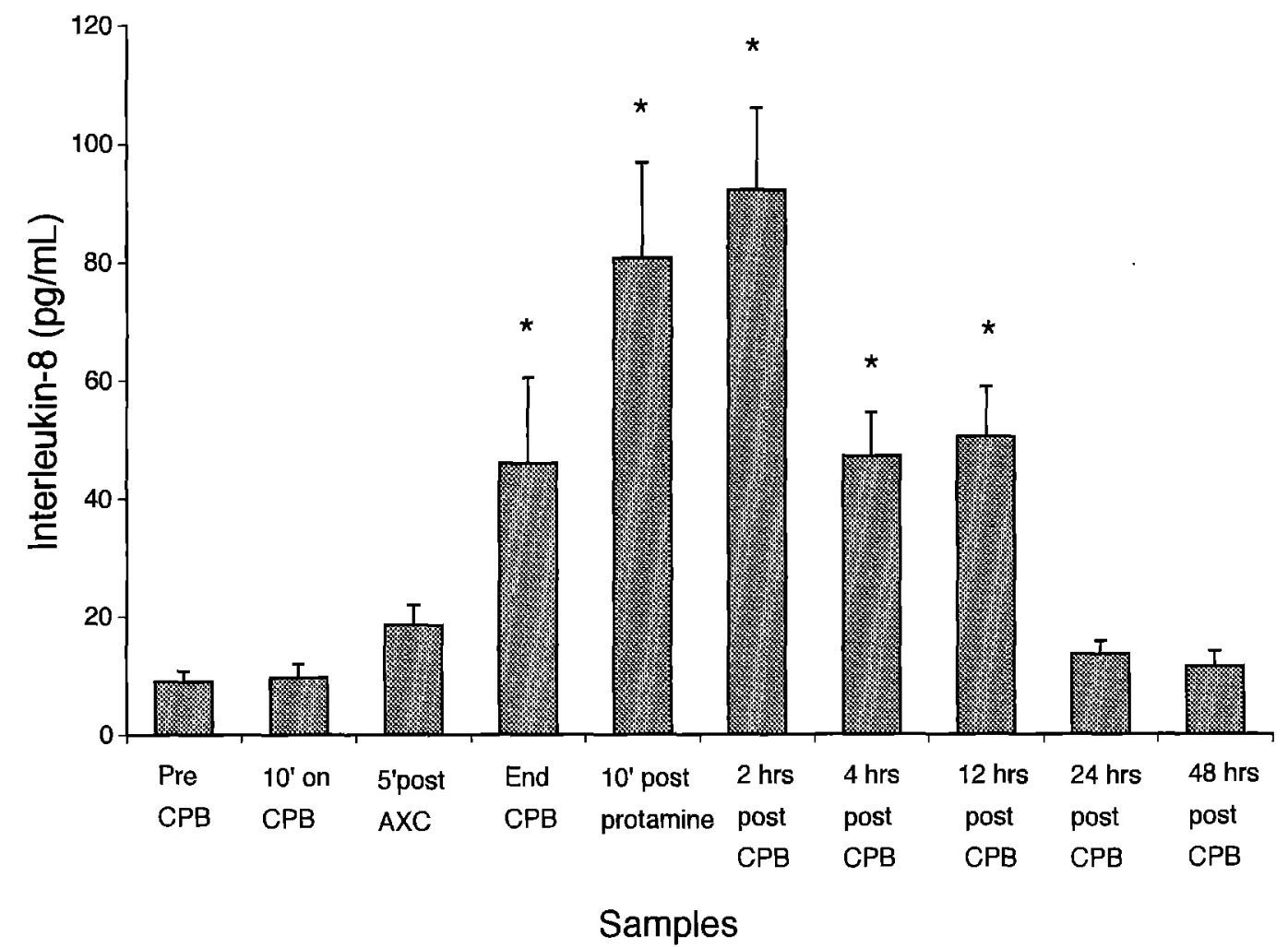

Fig. 2. Course of IL- 8 before, during, and after CPB in 11 infants. Values are expressed by mean \pm standard error of the mean. *Significant differences in IL-8 levels versus prebypass values $(p<0.05)$. $C P B$, Cardiopulmonary bypass; $A X C$, aortic crossclamp time. For specification of sample times, see text.

increased 4 hours after termination of CPB $(p<$ 0.05 ), reaching their peak values 24 hours after CPB $(351.6 \pm 304.0 \mathrm{pg} / \mathrm{ml} ; p<0.02)$. IL-10 levels were in the normal range on the second postoperative day. Fig. 3 shows the course of IL-10 before, during, and after CPB. No significant transpulmonary difference in IL-10 levels was noted during CPB. IL- 10 levels 4 and 24 hours after termination of CPB correlated negatively with the minimal rectal temperture during CPB (Spearman's correlation coefficient, -0.77 $[p<0.01]$ and $-0.89[p<0.0005]$, respectively). Fig. 4 shows the relationship between IL-10 measured 24 hours after CPB and minimal rectal temperature during CPB. IL-10 levels did not correlate with duration of CPB or aortic crossclamping. There was no correlation between IL-10 levels and TNF- $\alpha$ or IL-8 levels during or after CPB. IL-10 levels measured 4 and 24 hours after completion of CPB correlated with $\mathrm{PaO}_{2} / \mathrm{Fio}_{2}$ ratio calculated 12 hours after the operation (Spearman's correlation coefficient, $-0.80[p<0.01]$ and $-0.87[p<0.005]$, respectively). Fig. 5 shows the relationship between
IL-10 measured 24 hours after CPB and $\mathrm{PaO}_{2} / \mathrm{FiO}_{2}$ ratio calculated 12 hours after the operation.

\section{Discussion}

This study demonstrates cytokine balance related to CPB in infants undergoing cardiac operations. It confirms previous reports on TNF- $\alpha$ and IL-8 liberation during and after $\mathrm{CPB} .^{1,4,5,28-30}$ Data on TNF- $\alpha$ release remain nonetheless controversial. $^{28-30}$ The reason for the inconsistent systemic detection of this cytokine independent of the temperature regimen during CPB is not clear. In agreement with others, ${ }^{2,3,28-30}$ we observed a large interindividual variation in TNF- $\alpha$ and IL-8 production. Interindividual differences in TNF- $\alpha$ production are discussed in terms of genetic predisposition. ${ }^{31}$ In our series, patterns of TNF- $\alpha$ and IL- 8 release were similar, with progressive cytokine increase up to a peak value reached after protamine administration and 2 hours after termination of CPB, respectively, followed by the fall and normalization of these values from the first postoperative day on. These 


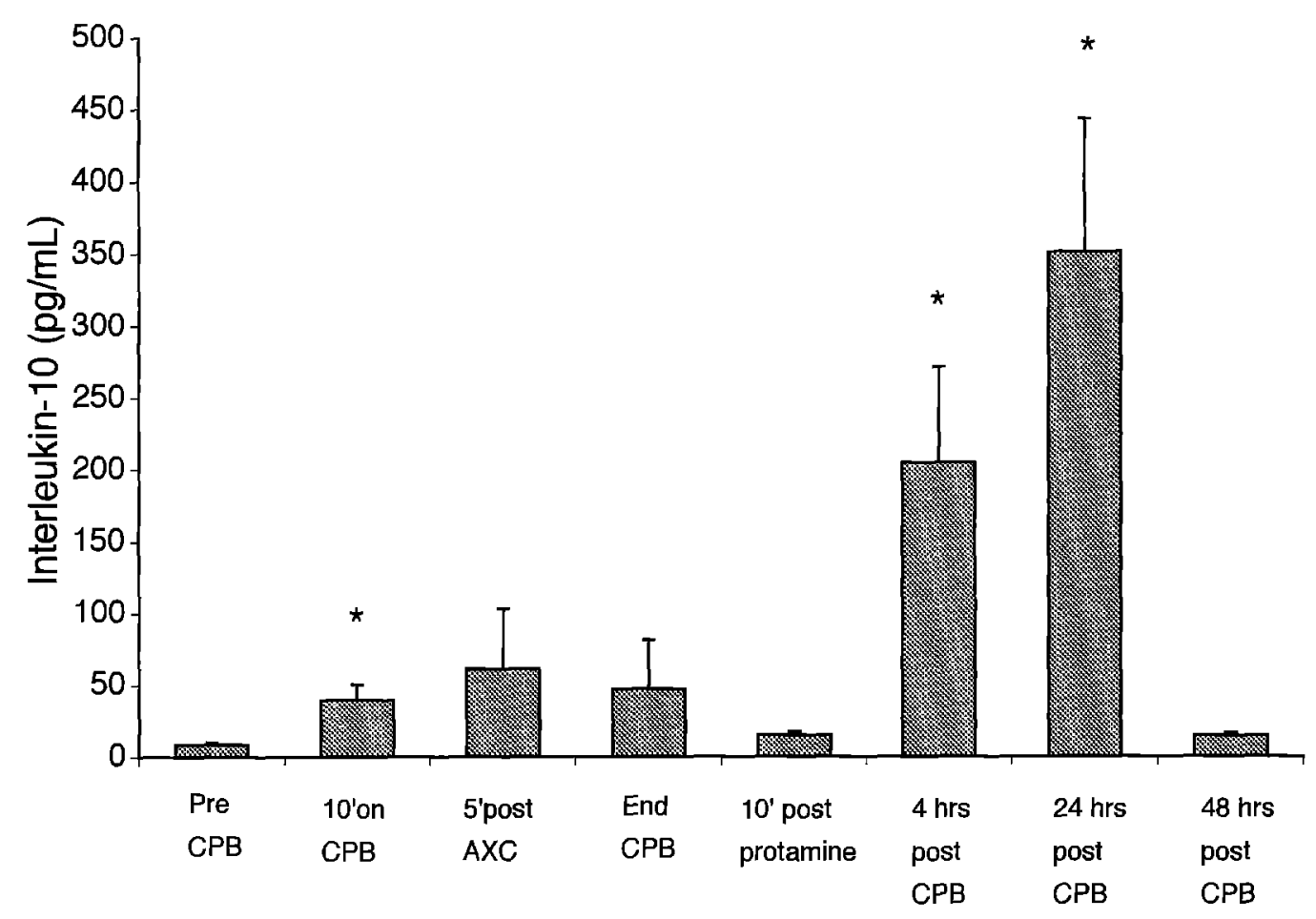

Samples

Fig. 3. Course of IL-10 before, during, and after CPB in 11 infants. Values are expressed by mean \pm standard error of the mean. *Significant differences in IL-10 levels versus prebypass values $(p<0.05)$. CPB, Cardiopulmonary bypass; $A X C$, aortic crossclamp time. For specification of sample times, see text.

parallel kinetics suggest the role of a common stimulatory mechanism acting early during CPB on cells producing TNF- $\alpha$ and IL-8. This mechanism could be complement activation with liberation of complement anaphylatoxins, the release of which always precedes the production of proinflammatory cytokines in the setting of $\mathrm{CPB}^{2,3}$ Cellular sources of TNF- $\alpha$ are mainly monocytes and macrophages, whereas IL-8 is also produced by neutrophils, endothelial cells, and numerous noncirculating cell types. $^{8,10}$ The absence of a significant TNF- $\alpha$ and IL-8 transpulmonary gradient during CPB in our patients-in particular after removal of the aortic crossclamp-excludes a predominant role of the pulmonary endothelium and pulmonary macrophages in the uptake or systemic release (or both) of those cytokines. Furthermore, the rapid increase of TNF- $\alpha$ and IL-8 after removal of the aortic crossclamp and the initiation of rewarming support the view that rewarming and ischemia-reperfusion mechanisms could be responsible, at least in part, for both the systemic TNF- $\alpha$ and IL-8 release. ${ }^{12,29,30}$

In our series, TNF- $\alpha$ and IL-8 levels measured during the first postoperative day correlated with maximal aspartate aminotransferase values. This relationship supports the suspected role of TNF- $\alpha$ in postoperative organ failure. ${ }^{9}$ Furthermore, it suggests that IL-8, by its chemotactic properties that might induce degranulation of stimulated neutrophils and proteolytic enzyme release, ${ }^{10,28}$ could also be implicated in postoperative tissue damage.

In addition to the production of proinflammatory cytokines related to $\mathrm{CPB}$, our results clearly demonstrate significant secretion of the antiinflammatory cytokine IL-10. In contrast to the release of TNF- $\alpha$ and IL-8, the pattern of IL-10 release was biphasic. A first significant peak of circulating IL-10 was observed as early as 10 minutes after induction of CPB. IL-10 levels then remained elevated until the end of CPB. Inasmuch as IL-10 is not detectable in plasma of healthy adults, ${ }^{23}$ admixture of IL-10 by the priming solution appears to be excluded here. Therefore our observation suggests immediate liberation of constitutive IL-10 from stimulated cells producing IL-10. ${ }^{18}$ Cellular sources of IL-10 are mainly cells from the monocyte-macrophage lin- 


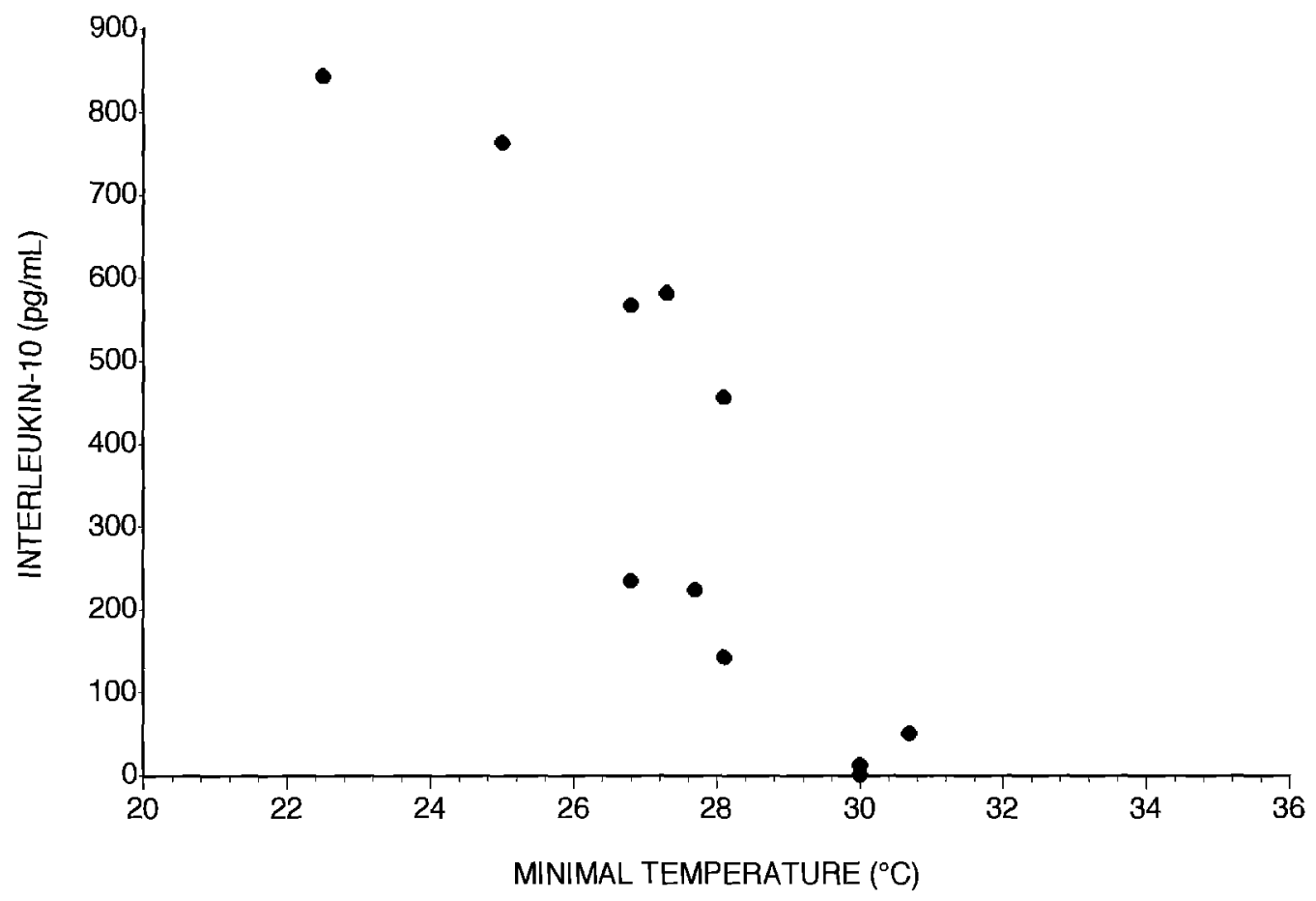

Fig. 4. Relationship between IL-10 measured 24 hours after termination of CPB and minimal rectal temperature during CPB $(n=11)$. Spearman's correlation coefficient $=-0.89(p<0.0005)$.

eage, but other circulating and noncirculating cells such as T- and B-lymphocytes and keratinocytes are also recognized as synthesizing IL-10. ${ }^{18}$ Pulmonary macrophages did not play an exclusive role in early IL-10 production in our patients, inasmuch as we did not observe a significant transpulmonary gradient of this interleukin during CPB. The stimulatory mechanism for the early IL-10 release that occurred independently from systemic TNF- $\alpha$ and IL-8 liberation remains at this time unclear. It must be mentioned that circulating cytokines do not strictly reflect local production, because their typical action is autocrine or paracrine and not endocrine. $.^{13} \mathrm{IL}-10$ is a pleiotropic antiinflammatory cytokine that deactivates monocytes and macrophages and inhibits the synthesis of proinflammatory cytokines such as TNF- $\alpha$ and IL- $8 .{ }^{16,17,20}$ As suggested by the inverse pattern of the kinetics of both TNF- $\alpha$ and IL- 8 on the one hand and IL-10 on the other hand, early IL-10 liberation during CPB could have modulated subsequent proinflammatory cytokine release.

A second IL-10 peak was observed 24 hours after termination of CPB. IL-10 levels rose from the early postoperative period on, clearly after the peak concentrations of TNF- $\alpha$ and IL-8 were observed. This delayed IL-10 release most probably corresponds to the classic pattern for inducible cytokines. ${ }^{13}$ In our series, the inducing stimulus could well have been TNF- $\alpha$, which, in contrast to other cytokines such as IL- $1 \alpha$, IL- $1 \beta$, and IL- 6 , has been shown to have a predominant role in human monocyte IL-10 synthesis. $^{24}$

Our results showing significant IL-10 release persisting 24 hours after $\mathrm{CPB}$ contrast with a recent observation in adult patients, in whom weak and transient IL-10 release occurred in response to CPB performed under moderate hypothermia. In this series, pretreatment with corticosteroids significantly increased IL-10 production, suggesting a modulatory effect of corticosteroids on IL-10 synthesis. ${ }^{26}$ The strong relationship we observed between circulating IL-10 levels both 4 and 24 hours after the operation and minimal rectal temperature measured during CPB, but not duration of CPB and aortic crossclamping, suggest that hypothermia per se could modulate IL-10 production. Thus temperture during CPB might influence IL-10 synthesis in response to $\mathrm{CPB}$ and, at least in part, explain the different results we observed compared with results in the adult series. Because IL-1 production in vitro has been shown to be inhibited by hypothermia, ${ }^{2}$ the latter, by enhancing IL-10 synthesis, could have a 


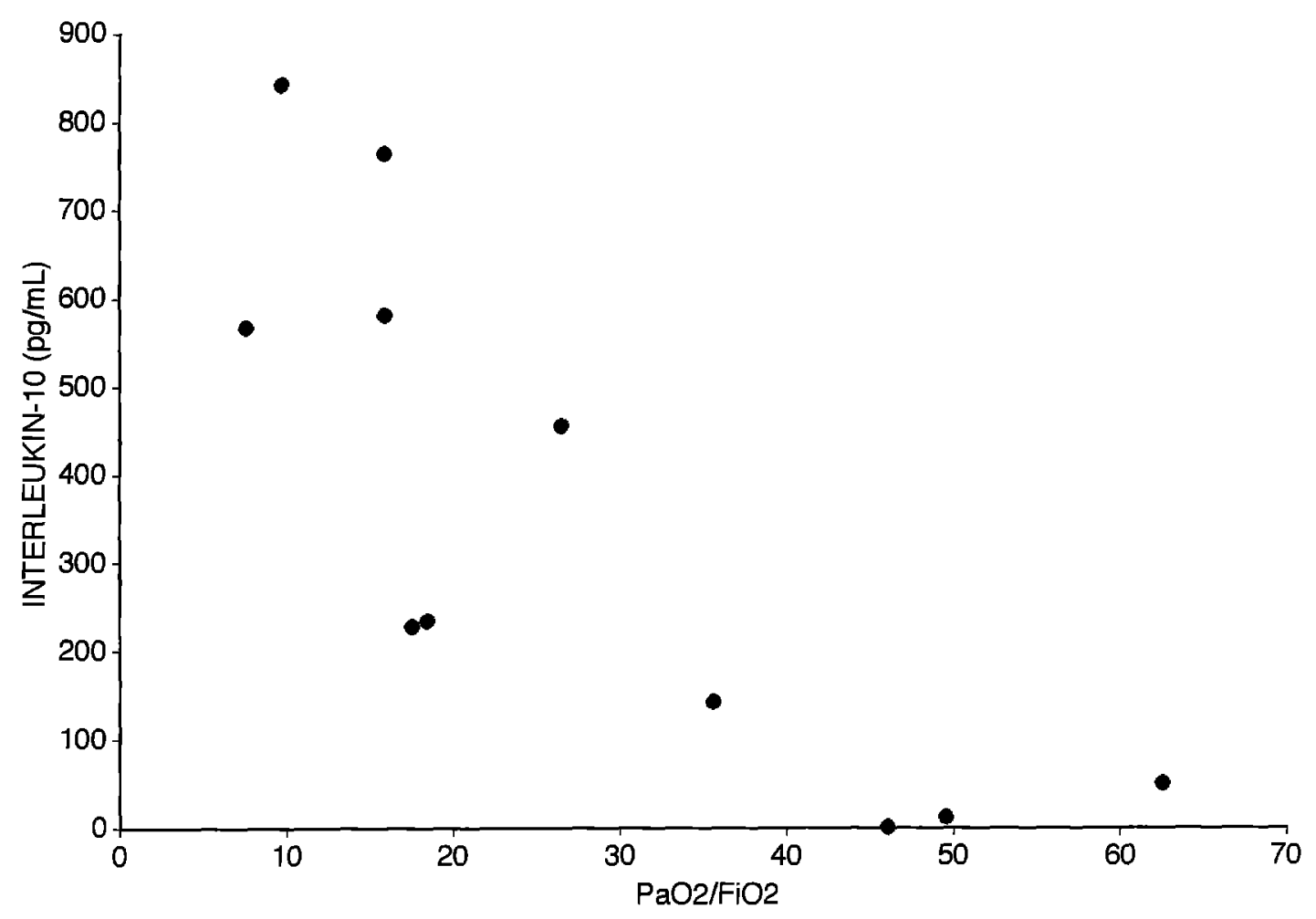

Fig. 5. Relationship between IL-10 measured 24 hours after termination of $\mathrm{CPB}$ and $\mathrm{PaO}_{2} / \mathrm{FiO}_{2}$ ratio calculated 12 hours after the operation $(n=11)$. Spearman's correlation coefficient $=-0.87(p<0.005)$.

positive influence on cytokine balance during CPB. The protective effect of high circulating IL-10 levels after CPB cannot be assessed in our patients because IL-10 levels correlate with postoperative morbidity, as suggested by the relationship between $\mathrm{PaO}_{2} / \mathrm{FiO}_{2}$ calculated during the first postoperative day and maximal IL-10 levels. Similar observations have been made in adult patients with sepsis in whom circulating IL-10 levels correlated with the presence of septic shock. ${ }^{23}$

In conclusion, our study demonstrates that, in addition to proinflammatory cytokine release, significant secretion of the antiinflammatory cytokine IL-10 occurs in infants undergoing CPB. The correlation between circulating IL-10 levels and degree of hypothermia suggests a modulating role of hypothermia in IL-10 production or secretion, or both. IL-10, by down-regulating the production of proinflammatory cytokines, may play a protective role in patients undergoing cardiac operations.

We thank Karen Buro, DiplMath, for advice in statistical analysis, our colleagues from the anesthesiologist and perfusionist staff, and the nurses from the pediatric intensive care unit for their help during the study.

\section{REFERENCES}

1. Casey WF, Hauser GJ, Hannallah RS, et al. Circulating endotoxin and tumor necrosis factor during pediatric cardiac surgery. Crit Care Med 1992;20:1090-6.

2. Haeffner-Cavaillon N, Rousselier N, Ponzio O, et al. Induction of interleukin- 1 production in patients undergoing cardiopulmonary bypass. J ThORAC CARDIOvasC SuRg 1989;98:1100-6.

3. Steinberg JB, Kapelanski DP, Olson JD, et al. Cytokine and complement levels in patients undergoing cardiopulmonary bypass. J ThORac Cardiovasc Surg 1993;106:1008-16.

4. Kalfin RE, Engelman RM, Rousou JA, et al. Induction of interleukin-8 expression during cardiopulmonary bypass. Circulation 1993;88:401-6.

5. Hennein HA, Ebba H, Rodriguez JL, et al. Relationship of the proinflammatory cytokines to myocardial ischemia and dysfunction after uncomplicated coronary revascularization. J Thorac Cardiovasc Surg 1994;108:626-35.

6. Kirklin JK, Westaby S, Blackstone E, et al. Complement and the damaging effect of cardiopulmonary bypass. J THORAC CARDIOVASC SURG 1983;86;845-57.

7. Seghaye MC, Duchateau J, Grabitz RG, et al. Complement activation during cardiopulmonary bypass in infants and children: relation to postoperative multiple organ failure. J Thorac Cardiovasc Surg 1993;106:978-87.

8. Tracey KJ, Cerami A. Tumor necrosis factor: an updated review of its biology. Crit Care Med 1993;21:S415-22.

9. Casey LC. Role of cytokines in the pathogenesis of cardiopulmonary-induced multisystem organ failure. Ann Thorac Surg 1993;56:S92-6. 
10. Van Damme J. Interleukin-8 and related molecules. In: Thomson A, ed. The cytokine handbook. London: Academic Press Limited, 1991:201-14.

11. Smith WB, Gamble JR, Clark-Lewis I, et al. Interleukin-8 induces neutrophil transendothelial migration. Immunology 1991;72:65-72.

12. Metinko AP, Kunkel SL, Standiford TJ, et al. Anoxiahyperoxia induces monocyte-derived interleukin-8. J Clin Invest 1992;90:791- 8 .

13. Vilcek $\mathbf{J}$, Le J. Immunology of cytokines: an introduction. In: Thomson A, ed. The cytokine handbook. London: Academic Press Limited, 1991:1-17.

14. Moore KW, O'Garra A, de Waal Malefyt R, et al. Interleukin-10. Annu Rev Immunol 1993;11:165-90.

15. Sironi M, Munoz C, Pollicino T, et al. Divergent effects of interleukin-10 on cytokine production by mononuclear phagocytes and endothelial cells. Eur J Immunol 1993;23: 2692-5.

16. Fiorentino DF, Zlotnik A, Mosmann TR, et al. IL-10 inhibits cytokine production by activated macrophages. J Immunol 1991;147:3815-22.

17. Cassatella MA, Meda L, Bonora $S$, et al. Interleukin-10 (IL-10) inhibits the release of proinflammatory cytokines from human polymorphonuclear leukocytes: evidence for an autocrine role of tumor necrosis factor and IL-1 in mediating the production of IL-8 triggered by lipopolysaccharide. J Exp Med 1993;178:2207-11.

18. Rennick D, Berg D, Holland G, et al. Interleukin-10: an overview. Prog Growth Factor Res 1992;4:207-27.

19. Cassatella MA, Meda L, Gasperini S, et al. Interleukin-10 (IL-10) upregulates IL-1 receptor antagonist production from lipopolysaccharide-stimulated human polymorphonuclear leukocytes by delaying mRNA degradation. J Exp Med 1994;179:1695-9.

20. Gérard C, Bruyns C, Marchant A, et al. Interleukin-10 reduces the release of tumor necrosis factor and prevents lethality in experimental endotoxemia. J Exp Med 1993;177: 547-50.

21. Pradier O, Gérard C, Delvaux A, et al. Interleukin-10 inhibits the induction of monocyte procoagulant activity by bacterial lipopolysaccharide. Eur J Immunol 1993;23:2700-3.

22. Mulligan MS, Jones ML, Vaporciyan AA, et al. Protective effects of IL-4 and IL-10 against immune complex-induced lung injury. J Immunol 1993;151:5666-74.

23. Marchant A, Deviěre J, Byl B, et al. Interleukin-10 production during septicaemia. Lancet 1994;343:707-8.

24. Derkx B, Marchant A, Goldmann M, et al. High levels of interleukin-10 during the initial phase of fulminant meningococcal septic shock. J Infect Dis 1995;171:229-32.

25. van der Poll $\mathbf{T}$, Jansen $\mathbf{J}$, Levi $\mathbf{M}$, et al. Regulation of interleukin 10 release by tumor necrosis factor in human and chimpanzees. J Exp Med 1994;180:1985-8.

26. Tabardel Y, Duchateau J, Schmartz D, et al. Corticosteroids increase blood interleukin-10 levels during cardiopulmonary bypass in men. Surgery [In press].

27. Nicolas F, Daniel JP, Bruniaux J, et al. Conventional cardiopulmonary bypass in neonates: a physiological approach-10 years' experience at Marie-Lannelongue Hospital. Perfusion 1994;9:41-8.

28. Finn A, Naik S, Klein N, et al. Interleukin-8 release and neutrophil degranulation after pediatric cardiopulmonary bypass. J Thorac Cardiovasc Surg 1993;105:234-41.

29. Frering B, Philip I, Dehoux M, et al. Circulating cytokines in patients undergoing normothermic cardiopulmonary bypass. J Thorac Cardiovasc Surg 1994;108:636-41.

30. Kawamura T, Wakusawa R, Okada $\mathrm{K}$, et al. Elevation of cytokines during open heart surgery with cardiopulmonary bypass: participation of interleukin 8 and 6 in reperfusion injury. Can J Anaesth 1993;40:1016-21.

31. Tracey KJ. TNF and Mae West or: death from too much of a good thing. Lancet 1995;345:75-6. 